\title{
Characterization of Beet Yellows Closterovirus-Specific RNAs in Infected Plants and Protoplasts
}

\author{
X-H. He, A. L. N. Rao, and R. Creamer
}

Department of Plant Pathology, University of California, Riverside 92521.

Accepted for publication 20 November 1996.

\begin{abstract}
He, X-H., Rao, A. L. N., and Creamer, R. 1997. Characterization of beet yellows closterovirus-specific RNAs in infected plants and protoplasts. Phytopathology 87:347-352.

Tetragonia expansa plants infected with a California isolate of beet yellows virus (BYV-60) contained multiple BYV-specific RNAs identified by Northern blot hybridization. These RNAs were identified by cDNA probes specific to six open reading frames (ORFs). One genomic RNA and five subgenomic (sg) RNAs representing the p65/p6.4, p64, p24, p22, and $\mathrm{p} 21$ ORFs were identified. A probe derived from the 3 -terminal ORF

(p21) hybridized to each of the sgRNAs, indicating the RNAs are $3^{\prime}$ coterminal. Hybridization with $5^{\prime}$ - and $3^{\prime}$-end probes indicated that preparations of BYV particles contained the genomic RNA as well as two additional RNA molecules corresponding in size to the coat protein (CP) sgRNA and an unidentified RNA. A Chenopodium quinoa protoplast system also was used to study BYV replication. The temporal accumulation of BYV-specific RNAs and CP was investigated in protoplasts transfected with purified virion RNA. Accumulation of genomic plus-strand RNA was evident as early as $15 \mathrm{~h}$ postinoculation. The development of this protoplast system is significant for studies of closterovirus replication.
\end{abstract}

Beet yellows virus (BYV) is the type member of the genus Closterovirus (6). It is transmitted semipersistently by aphid vectors to a wide range of dicotyledonous hosts and causes economically important losses in sugar beet crops worldwide. The virus particle is composed of $\sim 4,000$ protein subunits and encapsidates one singlestranded messenger-sense RNA of 15,480 nt $(3,7)$. The BYV genome is $5^{\prime}$ capped and has no poly(A) tail (15). Computer analysis of the RNA sequence of BYV reveals nine open reading frames (ORFs) potentially encoding viral proteins p295, p48, p6.4, p65, p64, p24, p22, p20, and p21. Protein p48 was predicted to be expressed via +1 ribosomal frameshifting as p295/p48 fusion protein $(348 \mathrm{~K})(3)$. Based on amino acid sequence similarity, this large fusion protein is predicted to contain methyltransferase (MTR), RNA helicase (HEL), and RNA-dependent RNA polymerase (POL) domains conserved in the Sindbis-like supergroup of positive-strand RNA viruses (11). Protein p6.4 contains a highly hydrophobic domain, which is possibly a membrane-associated region (1). The amino acid sequence of protein p65 is similar to that of the HSP70 heat-shock proteins (2), whereas protein p64 has marginal sequence similarity to proteins of the HSP90 family of heat shock proteins (16). Protein p22 is the coat protein (CP) (1), and protein p24 is a $\mathrm{CP}$-diverged duplicate $(1,5)$ and has been suggested to be a second structural protein responsible for the "rattlesnake" structure of BYV (4). Proteins p20 and p21 have no sequence similarity to any known proteins. Based on recent phylogenetic analyses of the POL, HEL, and MTR domains in replication-related proteins, the closteroviruses are proposed to be included in an order designated Tobamovirales as a new family, Closteroviridae, with the genus Closterovirus retained for BYV-related viruses (11).

The possible expression of the BYV genome via subgenomic (sg) RNAs was first reported by Dolja et al. (10). They analyzed dsRNA isolated from infected plant tissue by Northern blot hybridization with randomly primed BYV-specific cDNA as a probe and found not only the double-stranded counterpart of the full-length BYV

Corresponding author: R. Creamer; E-mail address: rebecca.creamer@ucr.edu

Publication no. P-1997-0121-05R

(C) 1997 The American Phytopathological Society
RNA, but five additional shorter segments of dsRNA. However, because the BYV cDNA sequence used as the probe was not characterized, it was not possible to determine the origins of the RNAs.

Although BYV was first reported in 1940 (32), little is known about the replication of BYV RNAs. This lack of characterization is due to the large size of the genome, which contributes to particle fragility and makes it difficult to assess virus titer in inocula used for insect or mechanical transmission. These problems can be largely overcome using protoplasts instead of intact tissues. We developed a protoplast system from Chenopodium quinoa to facilitate the investigation of BYV replication. Under our conditions, protoplasts are easily isolated and routinely infected with BYV virion RNA. In this paper, we report the characterization of BYV subgenomic (sg) RNAs in BYV-infected tissue as well as preliminary information on replication of BYV-specific RNAs obtained by the $C$. quinoa protoplast system.

\section{MATERIALS AND METHODS}

Isolation of virions, viral RNA, and dsRNAs from infected plants. The BYV California isolate (BYV-CA, which causes mild symptoms) and the 1960 isolate (BYV-60, which causes more severe symptoms in certain hosts) were propagated in Tetragonia expansa in a greenhouse and purified as in Rogov et al. (28). Virion RNA was extracted with sodium dodecyl sulfate (SDS) and phenol in the presence of bentonite (12). dsRNAs were isolated from young infected leaves according to the method of Valverde et al. (30). Purified RNAs were dissolved in water and stored at $-80^{\circ} \mathrm{C}$.

Isolation and transfection of $\boldsymbol{C}$. quinoa protoplasts. Approximately 45 days after planting in the greenhouse, $C$. quinoa leaves (about 6 to $7 \mathrm{~cm}$ long) were removed from plants, wiped with a cotton applicator to remove exudates, and cut with a razor blade into $0.5-\mathrm{cm}$ squares. The leaf squares were placed in a petri dish and covered with $10 \mathrm{ml}$ of enzyme solution containing $1 \%$ cellulase, $0.5 \%$ macerozyme, $0.1 \%$ driselase, and $0.55 \mathrm{M}$ mannitol, $\mathrm{pH}$ 5.9. After overnight incubation at room temperature, protoplasts were isolated and quantified as in Rao et al. (26).

Protoplasts $\left(2.0 \times 10^{5}\right.$ cells $)$ were transfected with BYV-CA virion RNA by directly resuspending pelleted protoplasts in 5 to $10 \mu \mathrm{l}$ 
of inoculum ( $1 \mu \mathrm{g}$ of BYV RNA), adding $150 \mu \mathrm{l}$ of $40 \%$ polyethylene glycol and $0.55 \mathrm{M}$ mannitol to $1.5 \mathrm{ml}$, and incubating on ice for 15 min. For mock inoculation, BYV RNA was omitted from the inoculum. After inoculation, the protoplasts were washed twice with $1.5 \mathrm{ml}$ of $0.55 \mathrm{M}$ mannitol and resuspended in $1 \mathrm{ml}$ of culture medium (26). The transfected protoplasts were incubated at $26^{\circ} \mathrm{C}$ under continuous illumination for up to $60 \mathrm{~h}$ without shaking. Protoplasts were harvested by centrifugation $(50 \times g$ for $3 \mathrm{~min})$ at desired times, and the pellets were stored at $-80^{\circ} \mathrm{C}$.

Extraction of RNA and proteins from protoplasts. The frozen pellets, each containing $\sim 2 \times 10^{5}$ protoplasts, were used for extracting total RNA and proteins. To isolate RNA, the pellets were suspended in $250 \mu \mathrm{l}$ of RNA extraction buffer (27). Bentonite was added to a final concentration of $2.5 \mathrm{mg} / \mathrm{ml}$, and an equal volume of phenol was added. The aqueous phase was reextracted with phenol prior to ethanol precipitation. The RNA pellet was resuspended in distilled water. Protein samples were prepared by resuspending the protoplast pellets in $50 \mu \mathrm{l}$ of grinding buffer (100 mM Tris, $\mathrm{pH} 8.0$,

TABLE 1. Comparison of the sizes of beet yellows virus (BYV) genomic and subgenomic RNAs, as predicted based on the known cDNA sequence and as measured in Northern blot hybridizations

\begin{tabular}{lcc}
\hline $\begin{array}{l}\text { Putative BYV } \\
\text { open reading frame }\end{array}$ & $\begin{array}{c}\text { RNA sizes } \\
\text { predicted (nt) }\end{array}$ & $\begin{array}{c}\text { RNA sizes } \\
\text { measured (nt) }\end{array}$ \\
\hline p295 & 15,480 & $14,500(\mathrm{G})$ \\
p48 & 7,593 & $\mathrm{NF}^{\mathrm{z}}$ \\
p65/p6.4 & $5,872 / 6,036$ & $6,100(\mathrm{a})$ \\
p64 & 4,170 & $4,350(\mathrm{~b})$ \\
p24 & 2,561 & $2,600(\mathrm{c})$ \\
p22 & 1,840 & $1,850(\mathrm{~d})$ \\
p20 & 1,229 & $\mathrm{NF}$ \\
p21 & 712 & $800(\mathrm{e})$ \\
\hline
\end{tabular}

${ }^{\mathrm{x}}$ From Agranovsky et. al. (3).

${ }^{y}$ Letters in parentheses refer to RNAs in Figure 1, lane 6.

${ }^{\mathrm{z}} \mathrm{NF}=$ not found in Northern blot.
$10 \mathrm{mM}$ EDTA, $5 \mathrm{mM}$ DTT). The protein concentration was estimated by the bicinchoninic acid protein assay (BioRad, Richmond, $\mathrm{CA}$ ), and samples for sodium dodecyl sulfate-polyacrylamide gel electrophoresis (SDS-PAGE) were treated as described by Laemmli (17).

Virions were purified from frozen protoplast pellets as in Rogov et al. (28). Encapsidated RNA was isolated from virions as in Reed and Falk (27). Virion CP was extracted from virions as in Laemmli (17).

Northern blot hybridization. For Northern blot analysis, RNA preparations were denatured with glyoxal and dimethyl sulfoxide, separated on $0.8 \%$ agarose gel (22), and transferred electrophoretically to Nytran Plus membranes (Schleicher \& Schuell, Keene, $\mathrm{NH})$. The 5'-terminal probe contained 1,906 nucleotides from the $5^{\prime}$ end of the BYV RNA. Gene-specific cDNA probes were prepared from BYV-CA cDNA by incorporation of 33 pmol $\partial-{ }^{32} \mathrm{P}$ dCTP into each gene cloned in pBlueScript-SK (Stratagene, La Jolla, CA) by nick translation (Amersham Corp., Arlington Heights, IL). For riboprobe synthesis, the clone containing the 3 -terminal ORF (p21) in pBlueScript-SK was used. T3 and T7 RNA polymerase transcripts derived from this clone were labeled with $\partial_{-}{ }^{32} \mathrm{P}$ UTP as described previously (26). The (+) probe was used for detection of minussense RNAs, and the (-) probe was used for detection of plussense RNAs. The amount of $(+)$ or $(-)$ probe added for detection was adjusted to ensure that probes would contain similar radioactive counts $\left(1 \times 10^{6} \mathrm{cpm} / \mathrm{ml}\right)$. Conditions of prehybridization and hybridization were essentially the same as described previously (26).

Western blot analysis. Equivalent amounts of total proteins $(100 \mu \mathrm{g})$ from each mock-inoculated and infected protoplast sample were separated on a 15\% SDS-PAGE gel (17) and electrophoretically transferred to polyvinylidene difluoride membranes (Whatman, Hillsboro, OR). The membranes were incubated with BYV $\mathrm{CP}$ polyclonal immunoglobulin $\mathrm{G}(1 \mu \mathrm{g} / \mu \mathrm{l})$ at a $1: 1,000$ dilution and alkaline phosphatase-conjugated goat anti-rabbit antibody (Bio$\mathrm{Rad})$ at a 1:2,000 dilution. Bound antibody was visualized with a nitro blue tetrazolium/bromo-chloro-indolyl phosphate substrate following the manufacturer's instructions (BioRad).

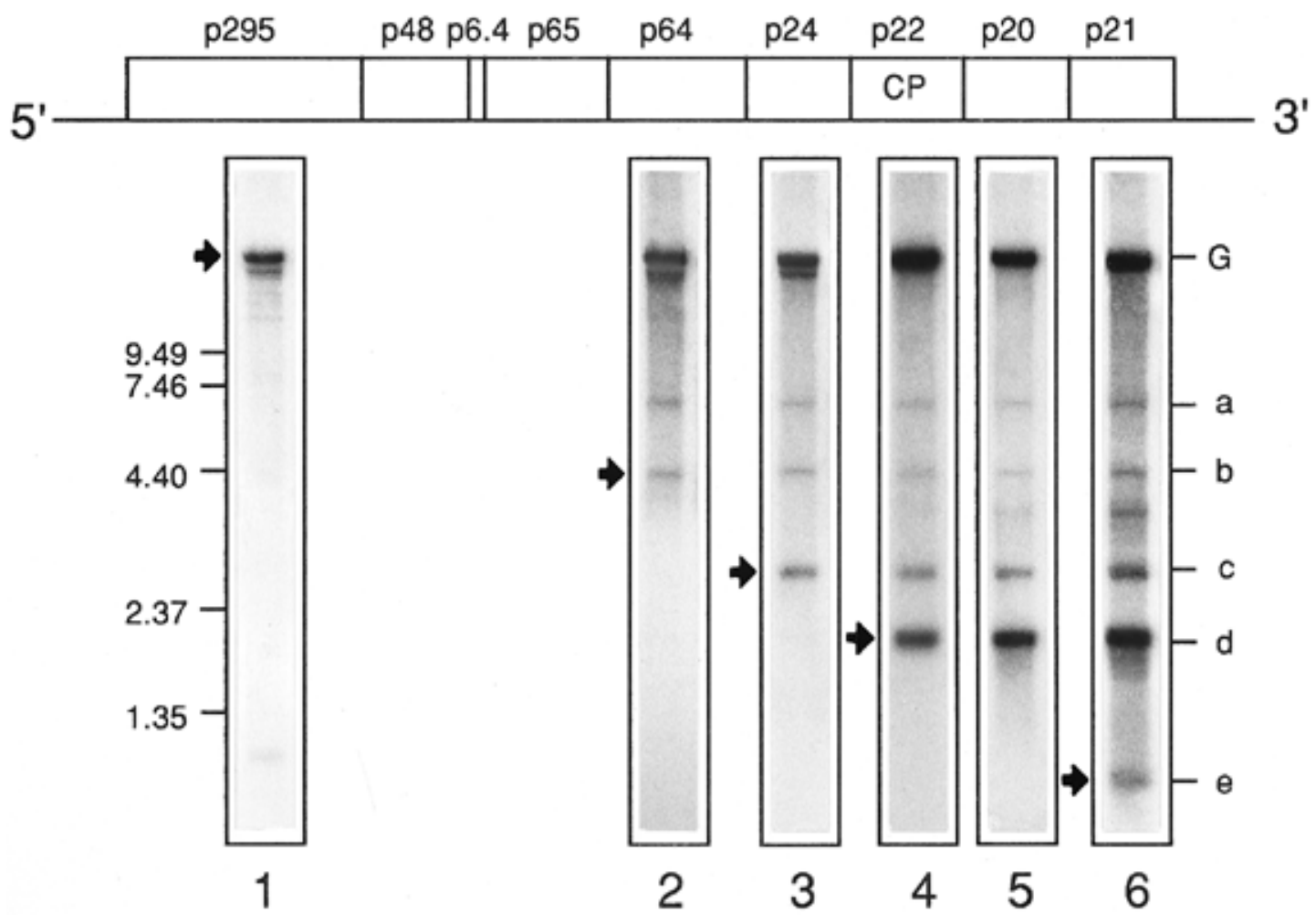

Fig. 1. Northern blot hybridization with six gene-specific cDNA probes. Lanes 1 through 6 , beet yellows virus (BYV) dsRNAs extracted from BYV-60-infected Tetragonia expansa leaves are marked by the genomic schematic at the top of the figure, indicating the source of the cDNA probe, which was prepared from BYV-CA. Arrows indicate the subgenomic RNA specified by each probe. The letters to the right of lane 6 indicate proposed genomic (G) and subgenomic (a through e) RNAs. RNA markers (in nucleotides) are shown to the left. $\mathrm{CP}=$ coat protein. 
Electron microscopy. Virion preparations were made by grinding BYV-infected $T$. expansa leaves or $C$. quinoa protoplasts infected for $30 \mathrm{~h}$ in $0.1 \mathrm{M}$ Tris- $\mathrm{HCl}, \mathrm{pH}$ 8.0. Preparations were placed on Formvar heavy carbon-coated grids, stained with $2 \%$ uranyl acetate, and examined with a Hitachi H-600 (Ibaraki, Japan) electron microscope.

\section{RESULTS}

Characterization of BYV sgRNAs in dsRNA preparations from infected leaves. The expected size of each BYV genomic and subgenomic RNA as predicted based on the published BYV cDNA sequence (3) is shown in Table 1. To confirm and further identify that the RNAs present in the dsRNA preparations corresponded to BYV genomic and subgenomic RNAs, probes specific to six ORFs of the BYV genome were used for Northern hybridization. The resulting RNA profiles are shown in Figure 1. The p295 probe hybridized to the largest RNA in the dsRNA preparation, labeled G (Fig. 1). This genomic RNA is the same size as the virion RNA (Fig. 2). The p6.4 and p65 probes are not currently available. The p64 probe hybridized to the genomic and two additional smaller RNAs, labeled a and b (Fig. 1). Except for the p20 probe, each succeeding cDNA probe, moving toward the $3^{\prime}$ end of the BYV genome, hybridized to a single additional RNA corresponding in size to the indicated ORF sgRNA. The 3'-terminal ORF (p21) cDNA probe hybridized to the genomic and five smaller RNAs, labeled a through e in descending order of size (Fig. 1), suggesting that RNAs a through e are $3^{\prime}$ coterminal. The RNAs that migrated between $G$ and a in lanes 1 through 3 and between $\mathrm{b}$ and $\mathrm{c}$ in lanes 5 and 6 did not correspond in size to any predicted sgRNAs, and their identity has not been determined.

The sizes of RNAs a through e were estimated by regression analysis of RNA mobilities measured in Northern blots, using known sizes of RNA standards (Table 1). Based on the results obtained

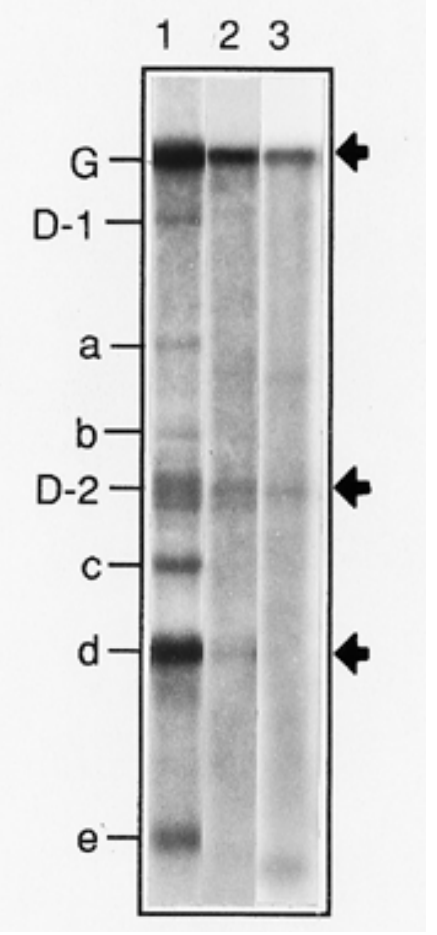

Fig. 2. Northern blot analysis of RNA extracted from purified virus particles (mixture of beet yellows virus [BYV] isolates BYV-CA and BYV-60, lanes 2 and 3) and dsRNA from BYV-CA-infected leaves (lane 1). Lanes 1 and 2 were hybridized with a $3^{\prime}$-terminal cDNA probe; lane 3 was hybridized with a $5^{\prime}$ terminal cDNA probe. The cDNA probes were prepared from BYV-CA. The letters to the left of lane 1 indicate proposed genomic $(\mathrm{G})$, subgenomic (a through e), and unidentified (D-1 and D-2) RNAs. Arrows indicate the RNAs detected from purified virus particles. from Northern hybridizations with gene-specific probes and in comparison to the predicted sizes, RNAs a through e were identified as sgRNAs for the p65/p6.4, p64, p24, p22 (CP), and p21 ORFs. The origin of RNA a needs further confirmation but is likely a sgRNA for both the p65 and p6.4 ORFs because of the close sizes of their predicted RNAs. The sgRNA for the p20 ORF was not detected in our system. The CP sgRNA appeared to be the most abundant of the BYV sgRNA species based on the intensity of the bands.

Comparison of dsRNA patterns from BYV-CA and BYV-60. Figure 3 shows the Northern blot hybridization of dsRNA extracted from BYV-CA (lanes 2 and 4) and BYV-60 (lanes 1 and 3) infected leaves, using 3'-terminal ORF (P21) and 5'-terminal probes. The number and sizes of sgRNAs were identical in dsRNA profiles between BYV-CA and BYV-60. In addition to the sgRNAs, an intense band of unknown identity with a mobility lower than RNA e was detected by a $5^{\prime}$ probe in dsRNA preparations from both virus isolates. In the BYV-60 dsRNA preparation, an RNA migrating in the area designated D-2 $(\sim 3.35 \mathrm{~kb})$ hybridized with both the $3^{\prime}$ and $5^{\prime}$ probes. In comparison, the intensity of the RNA band from the BYV-CA dsRNA preparation, which migrated in the D-2 area, was different when probed with a $5^{\prime}$ probe (weak intensity) and a $3^{\prime}$ probe (stronger intensity). In the area designated D-1 ( 11 kb), $3^{\prime}$ and $5^{\prime}$ probes detected several RNA species of various sizes from BYV-60 and BYV-CA dsRNA preparations. No dsRNA was detected from uninfected plant leaves by the $5^{\prime}$ and the $3^{\prime} \mathrm{cDNA}$ probes (data not shown).

Analysis of BYV virion RNA. To determine whether the uppermost band in the dsRNA preparations in Figure 1 represents the BYV genomic RNA and whether additional RNAs are encapsidated, we performed a Northern blot analysis of RNA extracted from purified BYV particles (mixture of BYV-CA and BYV-60) with the $3^{\prime}$ - and 5'-terminal probes. Both probes hybridized to the genomic RNA and an RNA band in the D-2 area (Fig. 2). The 3' probe also hybridized weakly to a band corresponding in size to the CP sgRNA, suggesting that the CP sgRNA and an RNA the

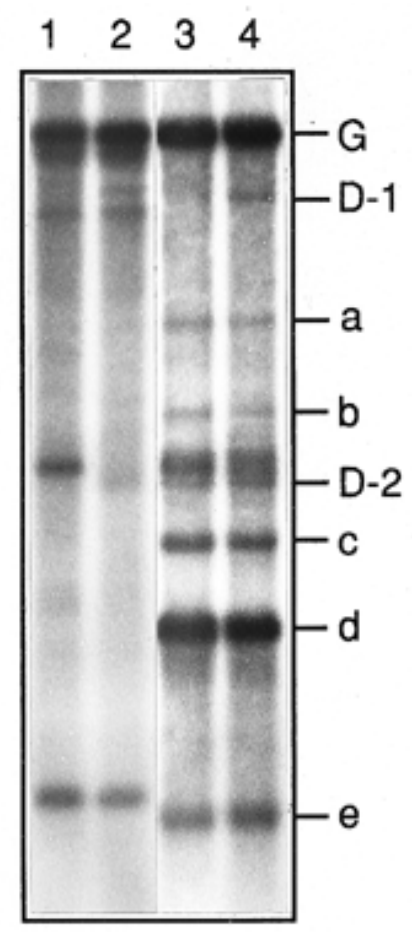

Fig. 3. Northern blot analysis of dsRNA extracted from leaves infected with beet yellows virus (BYV) isolates BYV-CA (lanes 2 and 4) and BYV-60 (lanes 1 and 3). Lanes 1 and 2 were hybridized with a 5 'terminal cDNA probe; lanes 3 and 4 were hybridized with a $3^{\prime}$-terminal cDNA probe prepared from BYV-CA. The letters to the right of lane 4 indicate proposed genomic $(\mathrm{G})$, subgenomic (a through e), and unidentified (D-1 and D-2) RNAs. 
size of D-2 also may be encapsidated. Based on the intensity of the bands, the genomic RNA seems to be the most abundant RNA encapsidated. A low molecular weight RNA migrating below e (Fig. 2, lane 3) did not correlate with any of the characterized sgRNAs and may have been an artifact of the virion isolation procedure.

Riboprobe strand specificity. The strand specificity of the riboprobes was tested by hybridizing these probes with virion RNA. Only the (-) probe reacted with virion RNA; the (+) probe did not react with the virion RNA (Fig. 4, lane 1, top and bottom). In dsRNA preparations, the relative amount of plus-sense RNA detected by the (-) probe was equal to that of minus-sense RNA detected by the (+) probe (Fig. 4, lane 9, top and bottom), indicating that use of these two complementary probes allows the ratio of plus- to minus-sense RNAs in infected cells to be estimated.

Accumulation of BYV genomic plus- and minus-sense RNAs in $C$. quinoa protoplasts. To study BYV genomic plus- and minus-sense RNA accumulation in C. quinoa protoplasts, equivalent amounts of total nucleic acids $(3.0 \mu \mathrm{g})$ from samples harvested at different times were analyzed by Northern hybridization with 3'-terminal ORF strand-specific RNA probes.

Both genomic plus- and minus-sense RNAs in transfected protoplasts were detected as early as $15 \mathrm{~h}$ postinoculation (p.i.) (Fig. 4 , lane 12, top and bottom), and a trace amount of virion RNA was detected at $10 \mathrm{~h}$ p.i. (Fig. 4, lane 11, top). The relative level of genomic plus-sense RNA (based on the band intensity) increased

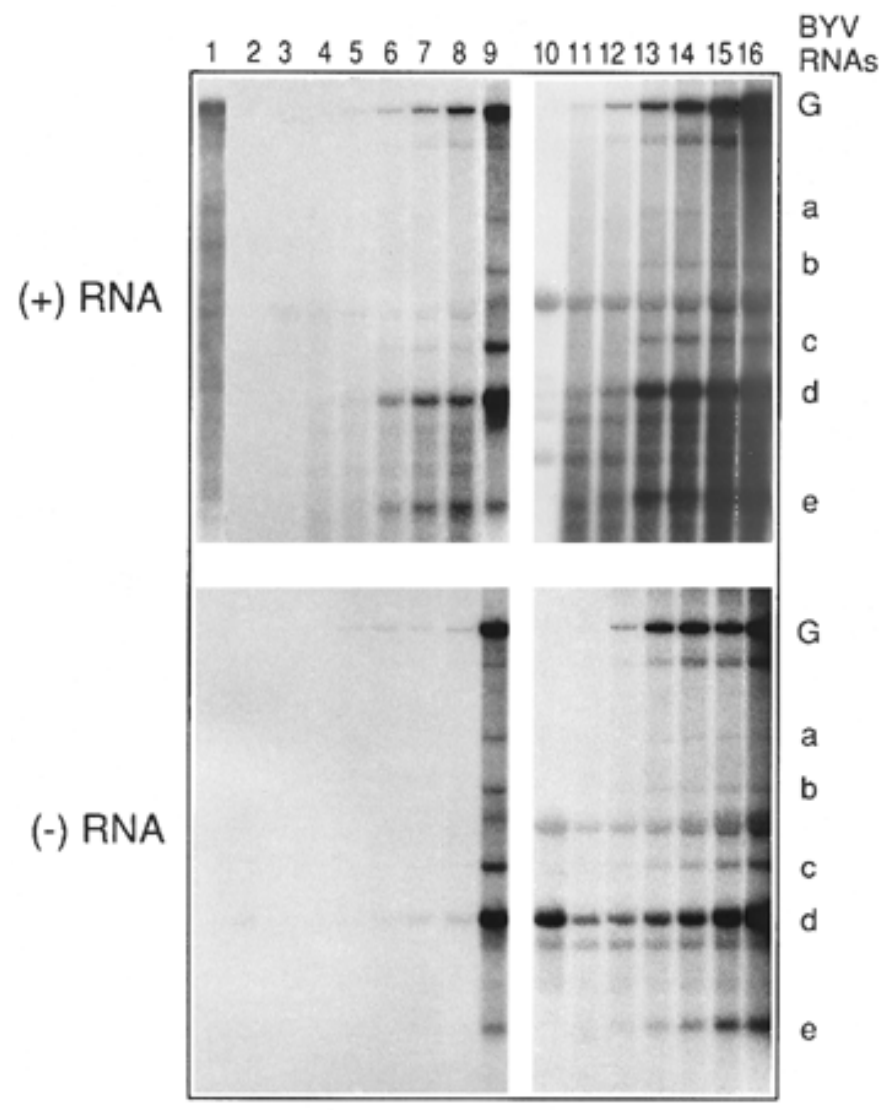

Fig. 4. Analysis of beet yellows virus (BYV) isolate BYV-CA genomic and subgenomic (sg) RNA accumulation in Chenopodium quinoa protoplasts by a ${ }^{32}$ P-labeled 3'-terminal (-) riboprobe to detect plus-sense RNAs (top panel) and (+) riboprobe to detect minus-sense RNAs (bottom panel). Lanes 1 and 9 were loaded with $50 \mathrm{ng}$ of BYV virion RNA and $4.0 \mu \mathrm{l}$ of undiluted dsRNA, respectively. Lanes 2 through 8 were loaded with $3 \mu \mathrm{g}$ of total RNA isolated from mock inoculated (lane 2) and infected protoplasts at the following postinoculation times (lanes 3 through 8): 10, 15, 20, 30, 40 and $60 \mathrm{~h}$. Blots in lanes 1 through 9 were exposed for $2 \mathrm{~h}$. Blots in lanes 10 through 16 were the same blots as those in lanes 2 through 8 , but were exposed overnight at room temperature. The position of genomic RNA (G) and sgRNAs (a through e) are shown on the right. with time during the first $60 \mathrm{~h}$ p.i., whereas the level of genomic minus-sense RNA did not increase between 20 and 60 h p.i. (Fig. 4). At all times tested, the genomic plus-sense RNA was more abundant than genomic minus-sense RNA.

Accumulation of BYV sgRNAs in $C$. quinoa protoplasts. Given our finding that BYV genomic and subgenomic RNAs are 3 ' coterminal, the $3^{\prime}$-terminal riboprobes (p21) would be expected to identify all genomic and subgenomic RNAs replicated in $C$. quinoa protoplasts. In the Northern blots shown in Figure 4, we detected five sgRNAs corresponding to five of the nine ORFs (labeled a through e), which also were found in dsRNA preparations from infected plants. The sgRNA d minus strand in the protoplasts comigrated with other RNAs (which were not detected by the minussense probe) in the agarose gel. The RNA migrating between $d$ and e did not correlate with any characterized BYV RNA and also was present in lanes containing mock samples, suggesting that it is not a viral RNA. The total RNA profile obtained from transfected protoplasts was the same as the dsRNA profile from infected plants (Fig. 4, lane 15 compared to lane 9, top or bottom).

Accumulation of CP and encapsidation of BYV RNA. To investigate the accumulation of $\mathrm{CP}, 100 \mu \mathrm{g}$ of total protein from transfected protoplast samples harvested at different times was analyzed by Western blotting (Fig. 5). CP was first detected at $20 \mathrm{~h}$ p.i., then increased until $60 \mathrm{~h}$ p.i.

When purified virions from transfected protoplasts at different times was analyzed for protein and RNA, the earliest time we detected virion RNA and CP was $30 \mathrm{~h}$ p.i. (Fig. 6A and B). The appearance and morphology of the virions obtained from transfected protoplasts were indistinguishable from those of infected plants (Fig. 7A and B).

\section{DISCUSSION}

The data obtained by Northern hybridization in this study confirm that the products of internal ORFs of BYV are expressed via the formation of a set of sgRNAs (10) and provide new evidence for the $3^{\prime}$-coterminal nature of five sgRNAs detected in our system. An analogous set of sgRNAs corresponding to ORFs 2 through 10 and their $3^{\prime}$-coterminal nature have been reported in plants infected with citrus tristeza virus (CTV) (13).

The lack of an identifiable sgRNA for $\mathrm{p} 48$ (predicted size $\sim 7.6$ $\mathrm{kb}$ ) agrees with the finding that $\mathrm{p} 48$ is expressed via +1 ribosomal

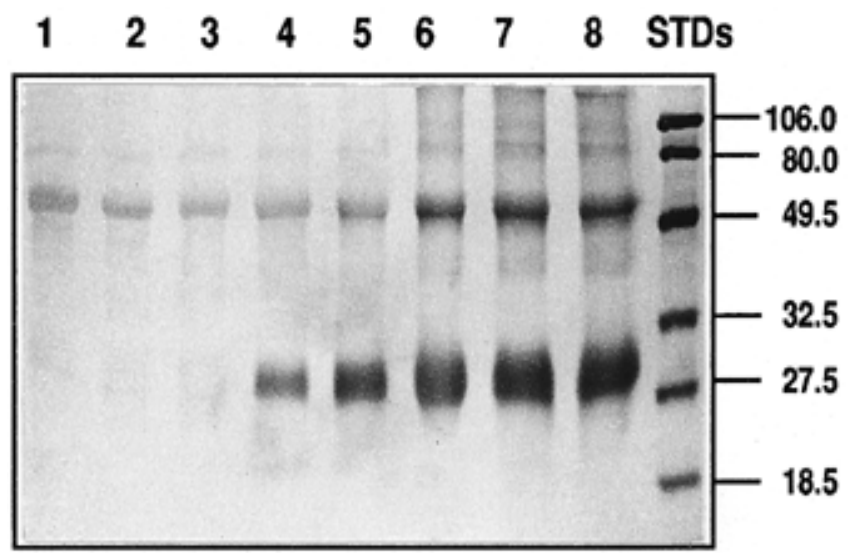

Fig. 5. Western blot analysis of beet yellows virus (BYV) coat protein (CP) accumulation in transfected Chenopodium quinoa protoplasts. Total protein was extracted as in Laemmli (17) from $2.0 \times 10^{5}$ transfected protoplasts separated on a $15 \%$ polyacrylamide sodium dodecyl sulfate gel and transferred electrophoretically to polyvinylidene difluoride membranes. The blot was analyzed with anti-BYV CP serum. Lanes 2 through 8 contain protein samples extracted from transfected protoplasts harvested at 10, 15, 20, 30, 40, 50, and $60 \mathrm{~h}$ postinoculation (p.i.), respectively. Lane 1 contains a protein sample from mock-inoculated protoplasts harvested at $40 \mathrm{~h}$ p.i. Protein molecular weight standards (STDs) are shown to the right. 
frameshifting instead of via sgRNA as proposed by Agranovsky et al. (3). The longest sgRNA most likely represents both the p6.4 and p65 ORFs, because their predicted RNA sizes differ by only 161 nt. These two RNAs could not be resolved by our electrophoresis system. Although p20 was detected in BYV-infected plants and protoplasts by a polyclonal antibody (data not shown), we failed to detect the sgRNA coding for the p20 with the 3 '-terminal ORF probe or even with the probe specific to the p20 ORF. This could be attributed to one of the following reasons: a low level of gene transcription, RNA instability, RNA expression other than via sgRNA, or RNA expression via functionally dicistronic sgRNA also coding for CP.

There were striking differences in the relative abundance of sgRNAs, as determined by band intensity. The sgRNA for the CP

\section{A}

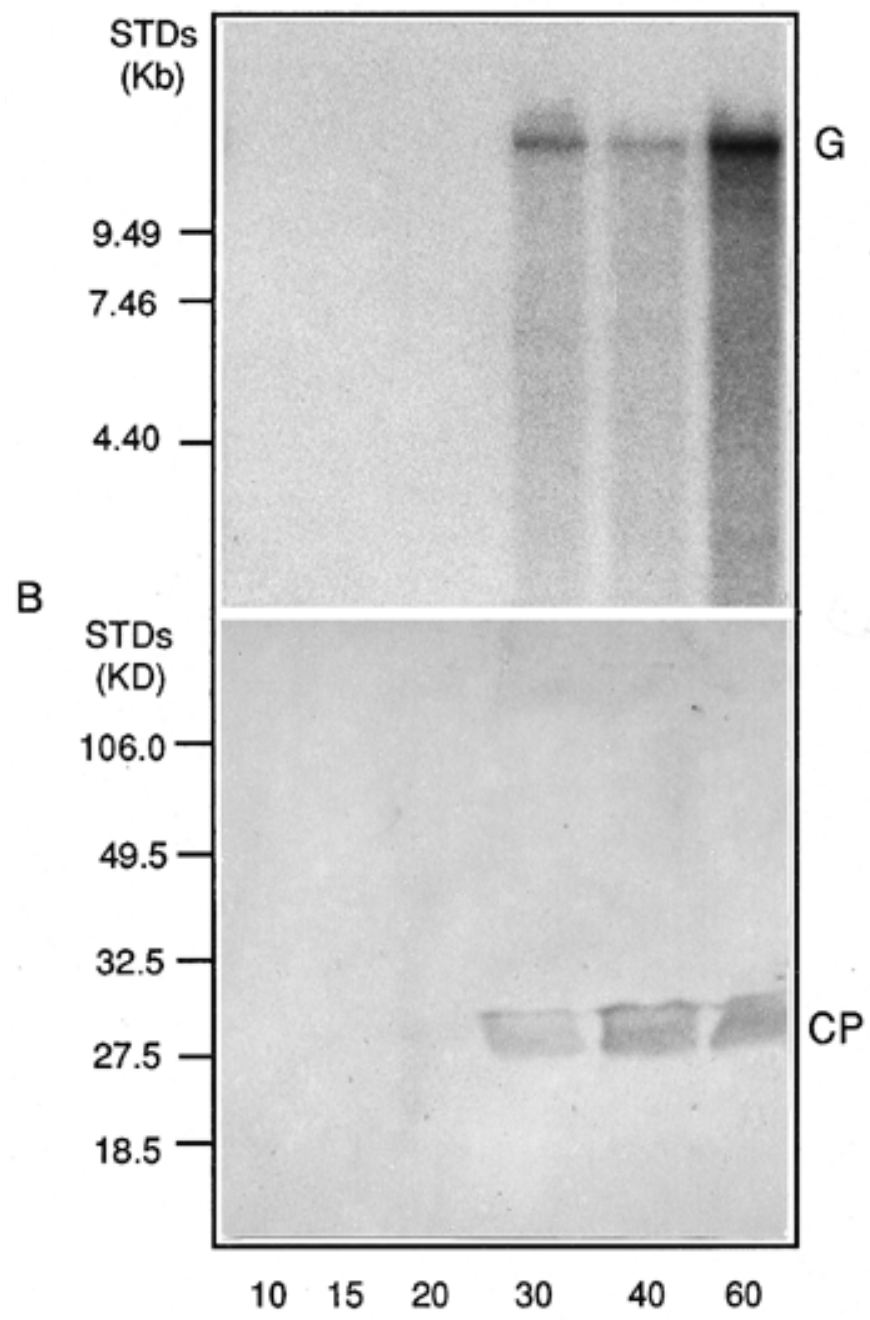

Time p.i. (h)

Fig. 6. Detection of beet yellows virus (BYV) virion RNA and virion coat protein $(\mathrm{CP})$ in transfected protoplasts. Virus particles were purified from $2.0 \times$ $10^{5}$ transfected protoplasts at incremental times postinoculation (p.i.). Virion RNA and protein were extracted from the virus preparations. A, Northern analysis of RNA samples from virion preparations at the indicated times after inoculation. Virion RNA was hybridized with a ${ }^{32} \mathrm{P}$-labeled 3'-terminal cDNA probe. The blot was exposed to film overnight. RNA standards are labeled to the left (STDs). The position of genomic RNA (G) is indicated to the right. B, Western blot of proteins from virion preparations at the indicated times after inoculation. Proteins were extracted as in Laemmli (17) from virion preparations, separated on a $15 \%$ sodium dodecyl sulfate-polyacrylamide gel, and transferred electrophoretically to polyvinylidene difluoride membranes. The blot was probed with anti-BYV CP serum. Low molecular weight protein standards are indicated to the left (STDs). The position of the BYV CP is indicated to the right. was the most abundant. This result was consistent between preparations of dsRNA from infected spinach leaves and total RNA from infected $C$. quinoa protoplasts. The relative abundance of BYV sgRNAs may be controlled genetically by the virus. Although the genome organization of CTV is very similar to that of BYV (11), the pattern of relative abundance of sgRNAs in CTV-infected plants was very different from that for BYV (13). For example, the sgRNA for the CP was the fourth most abundant in CTVinfected plants.

Dodds et al. $(8,9)$ and Moreno et al. $(24)$ found variation in dsRNA patterns between biologically distinct isolates of CTV. We did not find variation in the dsRNA pattern of sgRNAs from plants infected with BYV-CA and BYV-60, but the dsRNA patterns of several unknown RNA species varied considerably between the two isolates.

The existence of smaller than full-length CTV particles that encapsidate sgRNA and defective RNA molecules has been reported in CTV $(13,19,20)$. BYV has been thought to contain only one genomic RNA (15), but our Northern blot analyses of BYV virion RNA revealed the presence of the genomic as well as additional encapsidated RNAs corresponding in size to CP sgRNA and an unidentified RNA. We attribute these discrepancies to the different methods used for detection and variation between BYV isolates. We hypothesize that the unidentified BYV-60 RNA designated D-2 in Figure 3 that hybridized with both $3^{\prime}$ - and 5'-terminal probes could potentially be a defective RNA similar to that detected in CTV-infected plants (20). Because the group of RNAs

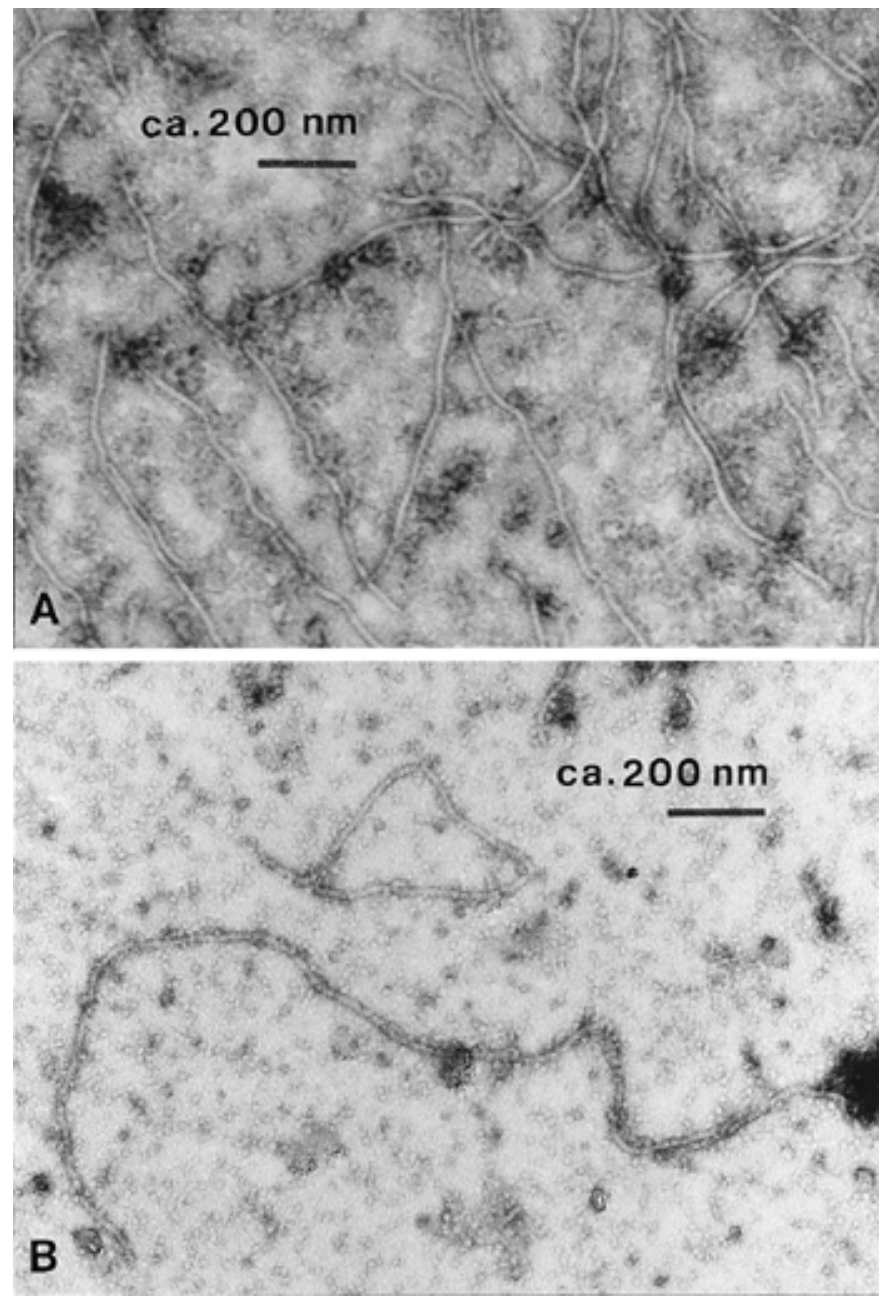

Fig. 7. Electron micrographs of virions detected in beet yellows virus (BYV)infected plants and protoplasts. Micrographs of A, virions from BYV-infected plants and B, homogenates of BYV-transfected protoplasts. Virions were stained with uranyl acetate prior to examination by transmission electron microscope. 
that migrated in the D-1 area did not hybridize with both the $3^{\prime}$ and the $5^{\prime}$ probes, we think that these more likely originated from quasispecific RNA degradation.

Like most RNA viruses of plants and animals $(14,18,21)$, BYV genomic plus- and minus-sense RNAs accumulated asymmetrically. The plus strands accumulated to a much higher level than the minus strands. The regulation mechanism is not yet known. In alfalfa mosaic virus infection, $\mathrm{CP}$ up-regulates plus-strand accumulation and down-regulates minus-strand accumulation, and these two functions can be mutated separately (31). In tobacco mosaic virus infection, Ishikawa et al. (14) found that deletion of the gene encoding the CP reduced the accumulation of plus-strand RNA by about $50 \%$ but did not affect the minus-strand accumulation. Thus, the accumulation of plus-and minus-sense RNAs of different viruses are likely regulated in different ways.

It has been demonstrated for several members of the Sindbislike supergroup of viruses, such as brome mosaic virus (23) and Sindbis (29), to which closteroviruses also belong, that sgRNA formation involves partial transcription of the genome-size minus strands rather than generation of autonomously replicating subgenomic-size minus strands. The subgenomic replicative forms are generally believed to be artifacts or byproducts of RNA replication. Although the possibility that closteroviruses use a dramatically different mechanism of sgRNA formation cannot be excluded, detection of subgenomic minus strands in our work is most likely explained by the presence of dsRNA in the preparations used for hybridization analysis. This potentially could be confirmed by quantitatively analyzing the minus strands present in dsRNA and total RNA preparations.

Elucidation of the replication of a virus is essential for a detailed understanding of its life cycle. To date, replication studies in closteroviruses have been initiated only for CTV (25). Analysis of BYV replication is still in an incipient stage. The protoplast system established here provides, for the first time, fundamental information on BYV replication in a single infected cell. The novel data that can be obtained by application of this system (e.g., localization of sgRNA promoters or characterization of defective RNAs) will provide valuable contributions to a rapidly developing area of closterovirus molecular biology.

\section{ACKNOWLEDGMENTS}

We thank B. Falk for the gift of beet yellows virus coat protein antisera, K. Harper for preparation of the figures, and M. N. Yassi and R. Richins for their reviews of and comments on this manuscript.

\section{LITERATURE CITED}

1. Agranovsky, A. A., Boyko, V. P., Karasev, A. V., Lunia, N. A., Koonin, E. V., and Dolja, V. V. 1991. Nucleotide sequence of the $3^{\prime}$-terminal half of beet yellows closterovirus RNA genome: Unique arrangement of eight virus genes. J. Gen. Virol. 72:15-23.

2. Agranovsky, A. A., Boyko, V. P., Karasev, A. V., Lunia, N. A., Koonin, E. V., and Dolja, V. V. 1991. Putative $65 \mathrm{KD}$ protein of beet yellows closterovirus is a homologue of Hsp 70 heat shock proteins. J. Mol. Biol. 217:603-610.

3. Agranovsky, A. A., Koonin, E. V., Boyko, V. P., Maiss, E., Frotschl, R., Lunia, N. A., and Atabekov, J. G. 1994. Beet yellows closterovirus: Complete structure and identification of a leader papain-like thiol protease. Virology 198:311-324.

4. Agranovsky, A. A., Lesemann, D. E., Maiss, E., Hull, R., and Atabekov, J. G. 1995. Rattlesnake structure of a filamentous plant RNA virus built of two capsid proteins. Proc. Natl. Acad. Sci. 92:2470-2473.

5. Boyko, V. P., Karasev, A. V., Agranovsky, A. A., Koonin, E. V., and Dolja, V. V. 1992. Coat protein gene duplication in a filamentous RNA virus of plants. Proc. Natl. Acad. Sci. USA 89:9156-9160.

6. Candresse, T., and Martelli, G. P. 1995. Genus closterovirus. Pages 461464 in: Virus Taxonomy. 6th Rep. Int. Committ. Taxon. Viruses. F. A. Murphy, C. M. Fauquet, D. H. L. Bishop, S. A. Ghabrial, A. W. Jarvis, G. P. Martelli, M. A. Mayo, and M. D. Summers, eds. Springer-Verlag, New York.

7. Carpenter, J. M., Kassanis, B., and White, R. F. 1977. The protein and nucleic acid of beet yellows virus. Virology 77:101-109.
8. Dodds, J. A., Jarupat, T., Lee, J. G., and Roistacher, C. N. 1987. Effects of strain, host, time of harvest, and virus concentration on double-stranded RNA analysis of citrus tristeza virus. Phytopathology 77:442-447.

9. Dodds, J. A., Jarupat, T., and Roistacher, C. N. 1988. Effect of host passage on dsRNAs of two strains of citrus tristeza virus. Pages 39-45 in: Proceedings of the 10th Conference of the International Organization of Citrus Virologists. L. W. Timmer, S. M. Garnsey, and L. Navarro, eds.

10. Dolja, V. V., Karasev, A. V., and Agranovsky, A. A. 1991. Organization of the beet yellows closterovirus genome. Pages 31-35 in: New Aspects of Positive-Strand RNA Viruses. M. A. Brinton and F. X. Heinz, eds. American Society of Microbiologists, Washington, DC.

11. Dolja, V. V., Karasev, A. V., and Agranovsky, A. A. 1994. Molecular biology and evolution of closteroviruses: Sophisticated build-up of large RNA genomes. Annu. Rev. Phytopathol. 32:261-285.

12. Fraenkel-Conrat, H., Singer, B., and Tsugita, A. 1961. Purification of viral RNA by means of bentonite. Virology 14:54-58.

13. Hilf, M. E., Karasev, A. V., Pappu, H. R., Gumpf, D. J., Niblett, C. L., and Garnsey, S. M. 1995. Characterization of citrus tristeza virus subgenomic RNAs in infected tissue. Virology 208:576-582.

14. Ishikawa, M., Meshi, T., Ohno, T., and Okada, Y. 1991. Specific cessation of minus-strand RNA accumulation at an early stage of tobacco mosaic virus infection. J. Virol. 65:861-868.

15. Karasev, A. V., Agranovsky, A. A., Rogov, V. V., Miroshnichenko, N. A., Dolja, V. V., and Atabekov, J. G. 1989. Virion RNA of beet yellows closterovirus: Cell-free translation and some properties. J. Gen. Virol. 70:241245.

16. Koonin, E. V., Mushegian, A. R., Ryabov, E. V., and Dolja, V. V. 1991. Diverse groups of plant RNA and DNA viruses share related movement proteins that may possess chaperone-like activity. J. Gen. Virol. 72:28952903.

17. Laemmli, U. K. 1970. Cleavage of structural proteins during the assembly of the head of bacteriophage T4. Nature (Lond.) 227:680-685.

18. Levintow, L. 1980. The reproduction of picornaviruses. Compr. Virol. 2: 109-169.

19. Mawassi, M., Gafny, R., Gagliardi, D., and Bar-Joseph, M. 1995. Populations of citrus tristeza virus contain smaller-than-full-length particles which encapsidate sub-genomic RNA molecules. J. Gen. Virol. 76:651659.

20. Mawassi, M., Karasev, A. V., Mietkiewska, E., Gafny, R., Lee, R. F., Dawson, W. O., and Bar-Joseph, M. 1995. Defective RNA molecules associated with citrus tristeza virus. Virology 208:383-387.

21. Marsh, L., Huntley, C. C., Pogue, G. P., Connel, J. P., and Hall, T. C. 1991. Regulation of (+):(-)-strand asymmetry in replication of brome mosaic virus RNA. Virology 182:76-83.

22. McMaster, G., and Carmichael, G. 1977. Analysis of single and doublestranded nucleic acids on polyacrylamide and agarose gels by using glyoxal and acidine orange. Proc. Natl. Acad. Sci. USA 74:4835-4839.

23. Miller, W. A., Dreher, T. W., and Hall, T. C. 1985. Synthesis of brome mosaic virus subgenomic RNA in vitro by internal initiation on (-)-sense genomic RNA. Nature (Lond.) 313:68-70.

24. Moreno, P., Guerri, J., and Munoz, N. 1990. Identification of Spanish strains of citrus tristeza virus by analysis of double-stranded RNA. Phytopathology 80:477-482.

25. Price, M., Schell, J., Grosser, J., Pappu, S. S., Pappu, H. R., Febres, V., Manjunath, K. L., Nibblet, C. L., Derrick, K. S., and Lee, R. F. 1996. Replication of citrus tristeza closterovirus in citrus protoplasts. Phytopathology 86:830-833.

26. Rao, A. L. N., Duggal, R., Lahser, F., and Hall, T. C. 1994. Analysis of RNA replication in plant viruses. Pages 216-236 in: Methods in Molecular Genetics: Molecular Virology Techniques. Vol. 4. K. W. Adolph, ed. Academic Press, San Diego, CA.

27. Reed, R. R., and Falk, B. W. 1989. Purification and partial characterization of beet yellow stunt virus. Plant Dis. 73:358-362.

28. Rogov, V. V., Karasev, A. V., and Agranovsky, A. A. 1993. Purification and some properties of an isolate of beet yellows virus from Ukraine. J. Phytopathol. 137:79-88.

29. Schlesinger, M. J. 1994. Sindbis and semliki forest viruses. Pages 13301333 in: Encyclopedia of Virology. R. G. Webster and A. Grenoff, eds. Academic Press, San Diego, CA.

30. Valverde, R. A., Dodds, J. A., and Heick, J. A. 1986. Double-stranded ribonucleic acid from plants infected with viruses having elongated particles and undivided genomes. Phytopathology 76:459-465.

31. Van Der Kuyl, A. C., Neeleman, L., and Bol, J. 1991. Role of alfalfa mosaic virus coat protein in regulation of the balance between viral plus and minus strand RNA synthesis. Virology 185:496-499.

32. Watson, M. A. 1940. Studies on the transmission of sugar-beet yellows virus by the aphid, Myzus persicae (Sulz). R. Soc. Lond. Proc. Ser. B 128:535-552. 